\title{
Arborização urbana como política de promoção de saúde e de planejamento urbano: um levantamento das capitais brasileiras
}

\section{Maria Elisa Diniz Bucci ${ }^{1}$, Carem Aparecida Mesquita ${ }^{2}$, Amanda Domingas Ediodato de Sousa ${ }^{3}$, Luiz Felipe Silva ${ }^{4}$ e Luciana Botezelli5}

\begin{abstract}
${ }^{1}$ Universidade Federal de Itajubá. Instituto de Recursos Naturais. Programa de Pós-Graduação em Meio Ambiente e Recursos Hídricos. Campus de Itajubá. Av. BPS, 1303. Itajubá-MG, Brasil (CEP 37500-903). E-mail: maelisadiniz@gmail.com.

${ }^{2}$ Universidade Federal de Alfenas. Instituto de Ciência e Tecnologia. Curso de Graduação em Engenharia Ambiental. Campus de Poços de Caldas. Rodovia José Aurélio Vilela, 11999. Poços de Caldas-MG, Brasil (CEP 37715-400).

${ }^{3}$ Universidade Federal de Alfenas. Instituto de Ciências da Natureza. Programa de Pós-Graduação em Ciências Ambientais. Campus de Poços de Caldas. Rodovia José Aurélio Vilela, 11999. Poços de Caldas-MG, Brasil (CEP 37715-400).

${ }^{4}$ Universidade Federal de Itajubá. Instituto de Recursos Naturais. Campus de Itajubá. Av. BPS, 1303. Itajubá-MG, Brasil (CEP 37500-903).

${ }^{5}$ Universidade Federal de Alfenas. Instituto de Ciência e Tecnologia. Campus de Poços de Caldas. Rodovia José Aurélio Vilela, 11999. Poços de Caldas-MG, Brasil (CEP 37715-400).
\end{abstract}

Resumo. A arborização urbana torna as cidades mais saudáveis e sustentáveis, contribuindo para melhoria da qualidade de vida e do bem-estar social. 0 presente trabalho teve como objetivo analisar os Planos Diretores de Arborização Urbana (PDAU's) pertencentes às capitais brasileiras. A metodologia utilizada buscou caracterizar tais documentos, quantificando-os e verificando sua relevância quanto uma ferramenta de gestão urbana. Os principais resultados demonstraram que $48 \%$ dos municípios estudados apresentavam e disponibilizavam estes documentos de forma online, enquanto $41 \%$ deles, apesar de prevê-los nas legislações municipais, não foram encontrados e $11 \%$ dos municípios não previam e nem apresentavam tais instrumentos. As regiões Norte e Nordeste são as que mais possuem capitais com mais PDAU's acessíveis. O PDAU do município do Rio de Janeiro-RJ é um documento bastante completo, apresentando todos os parâmetros necessários para a elaboração de um plano setorial deste tipo, enquanto que os de Aracaju-SE e João Pessoa-PB precisam ser revistos pois carecem de informações relevantes para a arborização destes municípios. A presença de PDAU's no Brasil auxiliam no planejamento urbano, uma vez que eles lidam com aspectos urbanísticos essenciais para a melhoria do planejamento urbano, regulando e

Recebido

$16 / 11 / 2020$

Aceito

$30 / 05 / 2021$

Disponível on line $31 / 05 / 2021$

Publicado

$31 / 05 / 2021$

Acesso aberto

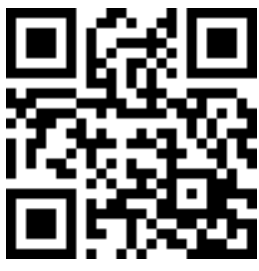

ISSN 2359-1412/RBGAS-2020-0168/2021/8/19/5/725

Rev. Bras. Gest. Amb. Sustent.

http://revista.ecogestaobrasil.net 
gerenciando a implantação e a manutenção das árvores presentes nas cidades.

Palavras-chave: Vegetação urbana; Cidades; Saúde coletiva; Sustentabilidade.

Abstract. Urban afforestation as a health promotion and urban planning policy: A survey of Brazilian capitals. Urban afforestation makes cities healthier and more sustainable, contributing to improving quality of life and social well-being. This study aimed to analyze the Urban Arborization Master Plans (UAMP's) belonging to the Brazilian capitals. The methodology used sought to characterize such documents, quantifying them and verifying their relevance as an urban management tool. The main results showed that $48 \%$ of the municipalities studied presented and made these documents available online, while $41 \%$ of them, despite providing for them in municipal legislation, were not found and $11 \%$ of the municipalities did not foresee or present such instruments. The North and Northeast regions have the most part of their capitals with the most accessible UAMP's. The UAMP of the municipality of Rio de Janeiro-RJ is a very complete document, presenting all the parameters necessary for the elaboration of a sectorial plan of this type, while those of Aracaju-SE and João Pessoa-PB need to be revised because they lack information relevant to the afforestation of these municipalities. The presence of UAMP's in Brazil helps in urban planning, since they deal with urban aspects essential to the improvement of urban planning, regulating and managing the implantation and maintenance of trees present in cities.

Keywords: Urban vegetation; Cities; Collective health; Sustainability.

\section{Introdução}

O intenso processo de urbanização e a falta de planejamento do uso do solo urbano, além de contribuir para o surgimento de danos ao meio ambiente, ocasiona transtornos relacionados à saúde coletiva. 0 planejamento urbano, quando utilizado em conjunto com políticas públicas eficazes, favorece a construção de cidades mais saudáveis (WHO, 2010). Um dos atributos que contribui para melhoria da qualidade de vida no meio urbano é a existência de espaços verdes e de arborização viária, já que conforme Bargos e Matias (2011), tais locais diminuem os efeitos negativos da urbanização.

Assim sendo, é importante que haja a elaboração de políticas públicas que assegurem o acesso igualitário destes espaços e melhorem a eficiência dos indivíduos arbóreos quanto promotores de saúde e agentes protetores do ambiente (Hunter et al., 2019). Sabe-se que o acesso à arborização não é igualitário para toda a população que reside no meio urbano, demonstrando, inclusive, as inequidades de saúde existentes. Nesse sentido, o acesso a um determinado recurso está associado à desigualdade na saúde física e mental, visto que a redução de iniquidades na saúde está interligada a diversos fatores, inclusive, com uma "distribuição de poder mais igualitária" (Dover e Belon, 2019). 
No Brasil, as cidades foram construídas visando à força de trabalho da população. Conforme descrito por Maricato (2015), a desigualdade e a segregação que ocorrem nas cidades brasileiras é fruto do planejamento presente nas mesmas, que privilegia a expansão do capital em detrimento da força de trabalho de classes que ocupam a base da pirâmide social. Em estudo realizado no estado do Sergipe, foram reveladas que as baixas expectativas de vida nas regiões noroeste e leste está associada às maiores taxas de pobreza, sendo as elevadas taxas de analfabetismo de idosos e desemprego preponderantes para estes resultados (Duque et al., 2018).

Foi observado em Belém-PA uma distinção entre a arborização das áreas elitizadas em relação à periferia do município. Os autores encontraram arborização vistosa e planejada em áreas com maior poder aquisitivo e vegetação arbustiva, pontual e mal planejada em locais periféricos (Lima et al., 2020). Além disso, conforme apurado por Duarte et al. (2017) em estudo realizado por levantamento de dados das regiões brasileiras no IBGE, quanto menor a renda média e pior as condições de moradia, menor é o acesso da população à arborização. Tal estudo ainda demonstrou que os locais "com menor incidência de extrema pobreza possuem maiores percentuais de arborização no entorno do domicílio". Tais estudos demonstram que a arborização urbana pode ser um indicativo da segregação social e injustiça ambiental.

Importante destacar a existência de estudo que demonstram os diversos benefícios advindos da arborização urbana. Existem estudos que correlacionam desde sua interferência na melhoria da saúde física e mental de frequentadores praticantes de atividades físicas nestes espaços (Dadvand et al., 2016; Liu et al., 2017; Gozalo et al., 2018), até mesmo a melhoria do microclima local (Shams et al., 2009; Dobbert e Zanlorenzi, 2014; Siqueira-Gay et al., 2017; Lucon e Longo, 2018).

Dessa forma, a adoção de instrumentos de gestão pode auxiliar no cotidiano das cidades e na melhoria da qualidade de vida da população, uma vez que favorecem o planejamento e a eficiência dos benefícios advindos da presença dos indivíduos arbóreos. Um destes instrumentos é o Plano Diretor de Arborização Urbana (PDAU), que visa a preservar e a monitorar a arborização existente na urbe e garantir a participação social frente às decisões tomadas em relação a esse aspecto (Sanches et al., 2008).

Isto posto, o presente trabalho teve como objetivo realizar uma análise dos PDAU's existentes em 27 capitais brasileiras, realizando um levantamento online das legislações pertinentes, de modo a possibilitar a realização de uma abordagem qualitativa e quantitativa, abordando aspectos relacionados à saúde coletiva e ao planejamento urbano.

\section{Material e métodos}

Este trabalho trata-se de uma pesquisa documental de caráter descritivo, conforme as definições de Gil (2002). Para realização deste, a coleta de dados e as análises realizadas seguiram o procedimento indicado a seguir (Figura 1).

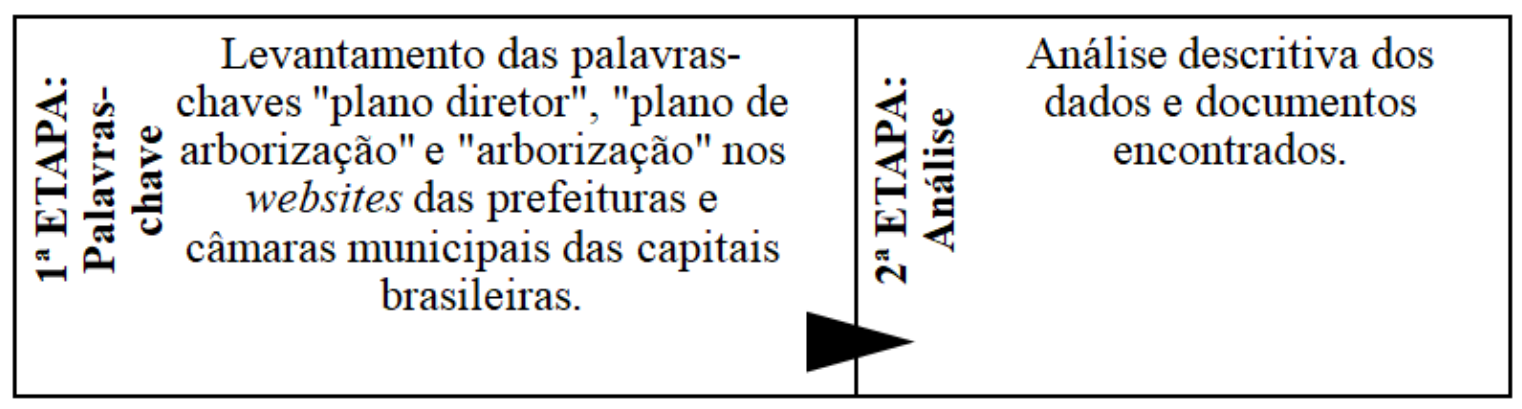

Figura 1. Fluxograma a ser seguido na elaboração do presente trabalho. 
Inicialmente, foi realizado um levantamento geral e quantitativo dos documentos encontrados. A delimitação inicial serviu para levantar os documentos disponibilizados de forma online, para a partir desses dados realizar uma análise qualitativa dos mesmos. A análise foi feita levando-se em consideração os seguintes aspectos: forma de apresentação; ano de elaboração; definições, diretrizes e objetivos dos PDAU's; educação ambiental; plano de manejo; produção de mudas e plantio; poda e corte; infrações e penalidades; medidas mitigadoras e compensatórias e especificações técnicas de plantio anexadas.

\section{Resultados e discussão}

A maioria dos municípios analisados não disponibilizava seus PDAU's (52\%), enquanto $48 \%$ deles foram encontrados de forma online (Figura 2). Manaus-AM, Salvador-BA, Fortaleza-CE, Goiânia-GO, Campo Grande-MS, Belém-PA, João Pessoa-PB, Recife-PE, Rio de Janeiro-RJ, Porto Alegre-RS, Porto Velho-RO, Aracaju-SE e Palmas-TO foram as 13 capitais que disponibilizaram este instrumento. Apesar disso, é válido destacar que a adesão de municípios ao desenvolvimento de planos setoriais voltados para a arborização tem sido discreta (Osako et al., 2016).

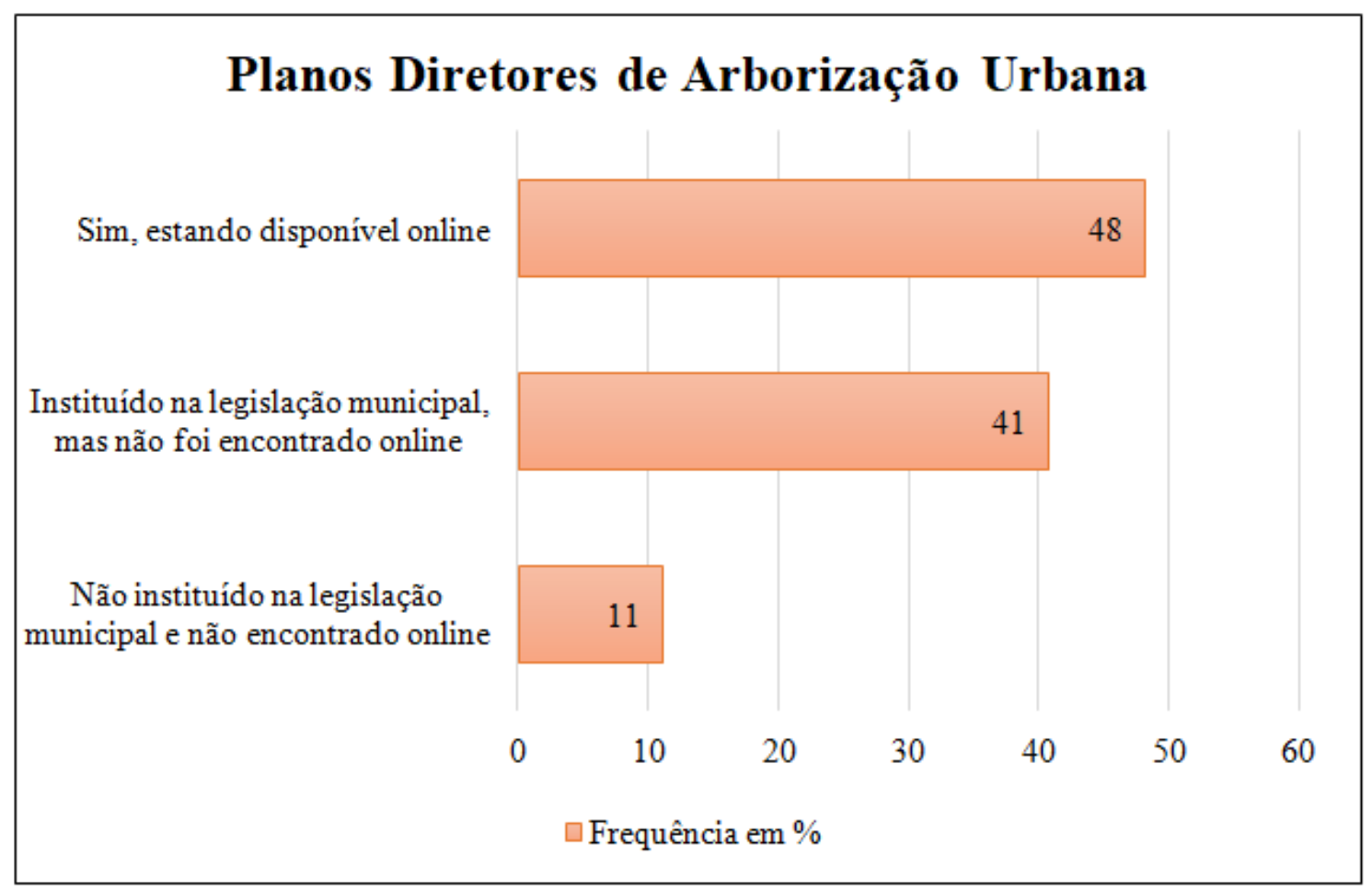

Figura 2. Distribuição dos PDAUs segundo disponibilidade, em porcentagem.

As regiões Norte e Nordeste são as que, dentre a frequência de PDAU's disponibilizados, apresentaram maior quantidade, totalizando nove municípios. Duarte et al. (2017) apuraram que, quanto menor a renda média e condições de moradia, menor é o acesso da população à arborização. Independente da intensidade da arborização urbana nestas regiões, é relevante frisar a importância dada à temática e ao planejamento deste instrumento nas localidades que possuem menor renda média mensal per capita (IBGE, 2020). 
A análise dos planos setoriais de arborização possibilitou caracterizar as políticas públicas existentes nestas localidades, já que todos eles apresentaram as principais definições, os objetivos e/ou diretrizes. Existe, ainda, uma disposição distinta dos planos que foram disponibilizados de forma online. Enquanto alguns tentam fazer uma caracterização da área e apresentam dados relacionados à arborização presente na forma textual (Fortaleza-CE, Goiânia-GO, Campo Grande-MS, Rio de Janeiro-RJ e Palmas-TO), outros são feitos na forma de legislação, incluindo as demais competências e regramentos sobre os indivíduos arbóreos presentes no meio urbano (Manaus-AM, Salvador-BA, Belém-PA, Porto Alegre-RS, Porto Velho-RO e Recife-PE). Nem todos os documentos apresentaram infrações e penalidades relacionadas à arborização urbana, sendo mencionadas apenas nos planos de Belém-PA, Campo Grande-MS, Goiânia-GO, Manaus-AM, Porto Velho-RO, Rio de Janeiro-RJ e Salvador-BA (Tabela 1).

Tabela 1. Formas de apresentação, infrações e penalidades e apresentação de diretrizes e objetivos nos PDAU's das 13 capitais brasileiras que os disponibilizam de forma online.

\begin{tabular}{|l|c|c|c|c|}
\hline Município & Ano & Apresentação & $\begin{array}{c}\text { Infrações e } \\
\text { penalidades }\end{array}$ & $\begin{array}{c}\text { Definições } \\
\text { principais, } \\
\text { diretrizes e/ou } \\
\text { objetivos }\end{array}$ \\
\hline Aracaju-SE & 2014 & Textual & Ausente & Presentes \\
\hline Belém-PA & 2012 & Textual e legislação & Presente & Presentes \\
\hline Campo Grande-MS & 2010 & Textual e legislação & $\begin{array}{c}\text { Presente na } \\
\text { legislação }\end{array}$ & Presentes \\
\hline Fortaleza-CE & 2020 & Textual* & Ausente & Presentes \\
\hline Goiânia-GO & 2008 & Textual e legislação & $\begin{array}{c}\text { Presente na } \\
\text { legislação }\end{array}$ & Presentes \\
\hline João Pessoa-PB & 2012 & Textual & Ausente & Breve apresentação \\
dos objetivos
\end{tabular}

Fonte: Próprios autores. *Plano apresentado na forma textual, mas ainda em construção.

A maioria daqueles apresentados na forma textual, conforme Tabela 1, conseguiram demonstrar o devido planejamento para a arborização urbana, destacando aspectos relevantes para a manutenção e conservação dos indivíduos arbóreos existentes no meio urbano. A exceção são os planos de Aracaju-SE e João Pessoa-PB, que foram apresentados de forma a faltar alguns marcos importantes para a caracterização e, até mesmo, a fiscalização da arborização destas áreas, sendo documentos mais simples e que que necessitam passar por atualização.

Alguns dos destaques foram os dos municípios de Fortaleza-CE e Rio de Janeiro-RJ. Ainda com o documento em construção, Fortaleza-CE apresentou um PDAU bastante elucidativo e participativo, estudado por Albuquerque et al. (2018). Estes pontuaram a importância de políticas públicas voltadas para a arborização urbana, uma vez que contribuem para a construção de um ambiente menos poluído e mais saudável. Já o PDAU 
do Município do Rio de Janeiro-RJ apresentou inventários da arborização do município, conseguindo demonstrar detalhadamente a caracterização deste atributo na cidade e elucidando caminhos para o planejamento e a manutenção correta dos indivíduos arbóreos. Silva et al. (2019) destacaram positivamente o PDAU do Rio de Janeiro-RJ, evidenciando, inclusive, a possibilidade de utilizá-lo como exemplo para a elaboração de outros planos setoriais de arborização de cidades de grande porte.

Em relação àqueles PDAU's que se apresentaram na forma de legislação, os que mais tiveram destaque foram os de Porto Velho-RO e Manaus-AM, trazendo todos os tópicos necessários para planejar e gerir a arborização presente no meio urbano. Observou-se que os planos apresentados na forma de legislação trouxeram as diretrizes necessárias para o planejamento e a manutenção da arborização urbana dos municípios analisados, no entanto, nem todos os planos apresentavam as infrações e respectivas penalidades.

Das 13 capitais com PDAU's disponibilizados online, apenas cinco realizaram um diagnóstico e caracterização da arborização urbana, representando uma parcela de 38,5\% (Campo Grande-MS, Fortaleza-CE, Goiânia-GO, Palmas-TO e Rio de Janeiro-RJ). Ainda assim, Palmas-TO não disponibilizou o documento de Diagnóstico de Arborização Urbana do município citado no PDAU referente, trazendo apenas os parâmetros sobre arborização urbana que seriam coletados. Em relação aos parâmetros encontrados nos PDAU's analisados, foi verificado maiores ocorrências relacionadas à localização e distribuição os indivíduos arbóreos existentes no município (15,2\%), assim como dados relacionados à composição florística $(15,2 \%)$ e de conflitos existentes entre a arborização e os equipamentos urbanos (12,1\%) (Figura 3). Já aspectos relacionados à caracterização do indivíduo arbóreo como copa, idade, diâmetro ou circunferência na altura do peito (DAP/CAP), porte e condição fitossanitária estão presentes 33,3\% dos PDAU's (Figura 3). 0 histórico da arborização e sua valorização cultural foram pontuados nos Municípios de Fortaleza-CE e Goiânia-GO, demonstrando a relevância deste atributo para estas cidades.

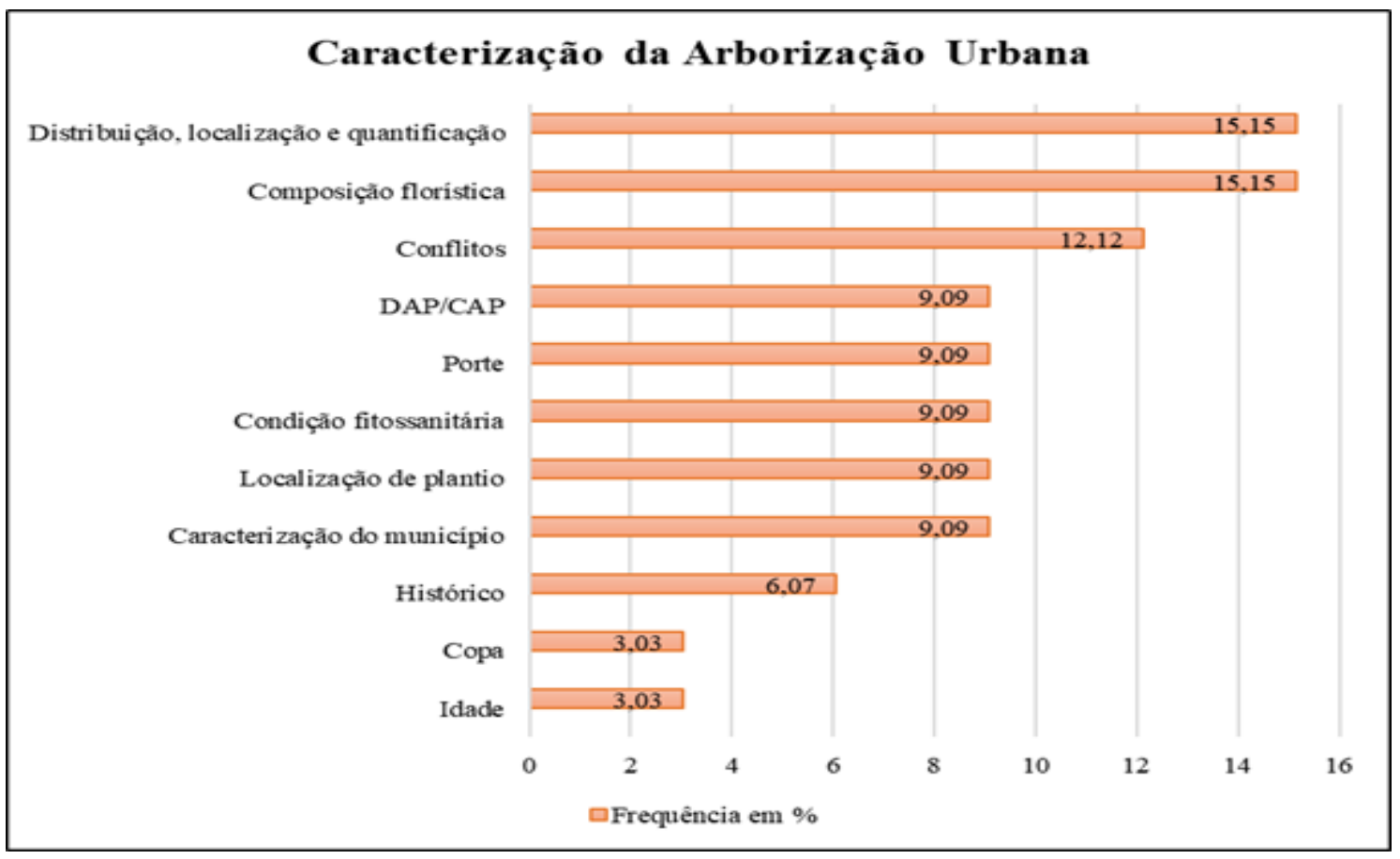

Figura 3. Distribuição dos parâmetros observados na caracterização da arborização urbana, em porcentagem, presentes nos PDAU's das capitais brasileiras. 
Sabe-se que a arborização urbana deve ser projetada em conjunto com o planejamento urbano para favorecer a promoção de saúde advinda dos seus diversos benefícios (Lee et al., 2015). Isto posto, é importante realizar o manejo e a manutenção correta das árvores localizados no meio urbano. Tal manejo e manutenção foram observados em 12 dos PDAU's analisados, excetuando na Capital da Paraíba, João Pessoa, representando $92,3 \%$ dos dados analisados.

A maioria dos dados encontrados está limitada à realização de podas $(12,9 \%)$, a necessidade de atender regramentos específicos e ordens técnicas sobre a supressão, a poda e o transplante de indivíduos arbóreos $(8,6 \%)$, visitas periódicas nas áreas para observar a condição fitossanitária e a necessidade de alguma intervenção nestes indivíduos $(7,5 \%)$ e a prática de tutorar e/ou retutorar $(6,5 \%)$, realizar tratamento fitossanitários $(5,4 \%)$, irrigação $(4,3 \%)$ e adubação $(3,2 \%)$, monitorar $(4,3 \%)$ e remover mudas que não tiveram o desenvolvimento desejado e, se possível, replantá-las $(6,5 \%)$ (Figura 4). A elaboração de um plano de manejo e a construção de um inventário da arborização urbana também foram pontuados nos PDAU's analisados, totalizando 7,5\% do total (Figura 4).

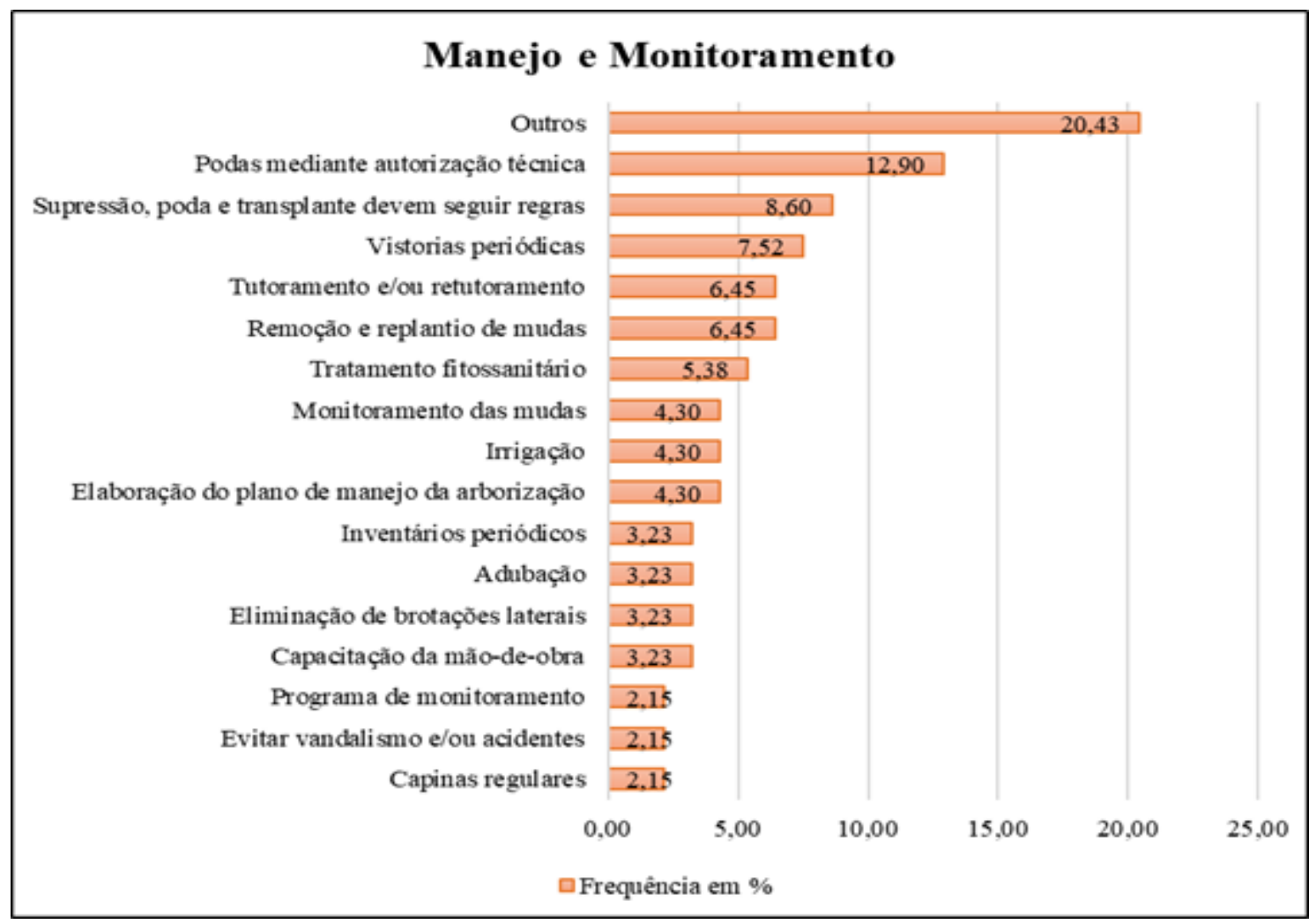

Figura 4. Distribuição dos parâmetros observados no manejo e no monitoramento da arborização urbana, em porcentagem, presentes nos PDAU's das capitais brasileiras, sendo "Outros" os seguintes parâmetros: reuniões técnicas, reposição de árvores pré-existentes, recuperação de calçadas, recomendações para conservação das árvores durante obras, podas em datas estratégicas, plantio, nutrição mineral do solo, não utilizar árvores para suporte de equipamentos, localização de plantios a serem realizados, levantamento de problemas relacionados à arborização, levantamento de espécies favoráveis à remoção, levantamento de espécies a serem utilizadas, levantamento do índice de mortalidade de mudas, dendrocirurgia, croqui de acompanhamento, atividade de manutenção desenvolvidas, atendimento de demanda da população, área livre e análise de remoção de árvores. 
A realização de podas e de cortes, como pode ser observado pela Figura 4, é uma importante técnica de manejo para a arborização urbana. Conforme Cunha et al. (2020), um dos principais conflitos existentes entre as árvores e os equipamentos urbano do Município de Valença-RJ é relacionado à fiação elétrica. Assim sendo, foram observados tópicos relacionados às podas em 12 PDAU's distintos, excetuando-se o de João Pessoa-PB. Em 10,8\% dos casos é necessário realizar um diagnóstico fitossanitário para saber se aquele indivíduo arbóreo realmente precisa passar pelo processo de poda ou corte e a existência de tipos distintos de poda, como a de adequação, a de segurança e a de formação totalizaram $21,6 \%$ dos dados analisados. Além disso, foram pontuados os responsáveis pelas podas, que iam desde as secretarias de meio ambiente dos municípios, até mesmo, às companhias de energia (em 14,5\% dos PDAU's). A geração de multas para aqueles que infringissem as regras pontuadas referentes a este parâmetro foi notada em $8,4 \%$ dos documentos analisados. Por fim, um dos quesitos relevantes observados foi a necessidade de reaproveitar os resíduos gerados pelas podas em $6,0 \%$ dos casos, demonstrando, inclusive, técnicas de destinação corretas a serem utilizadas neste aspecto. Dados referentes a podas e corte de árvores foram relacionados na Figura 5.

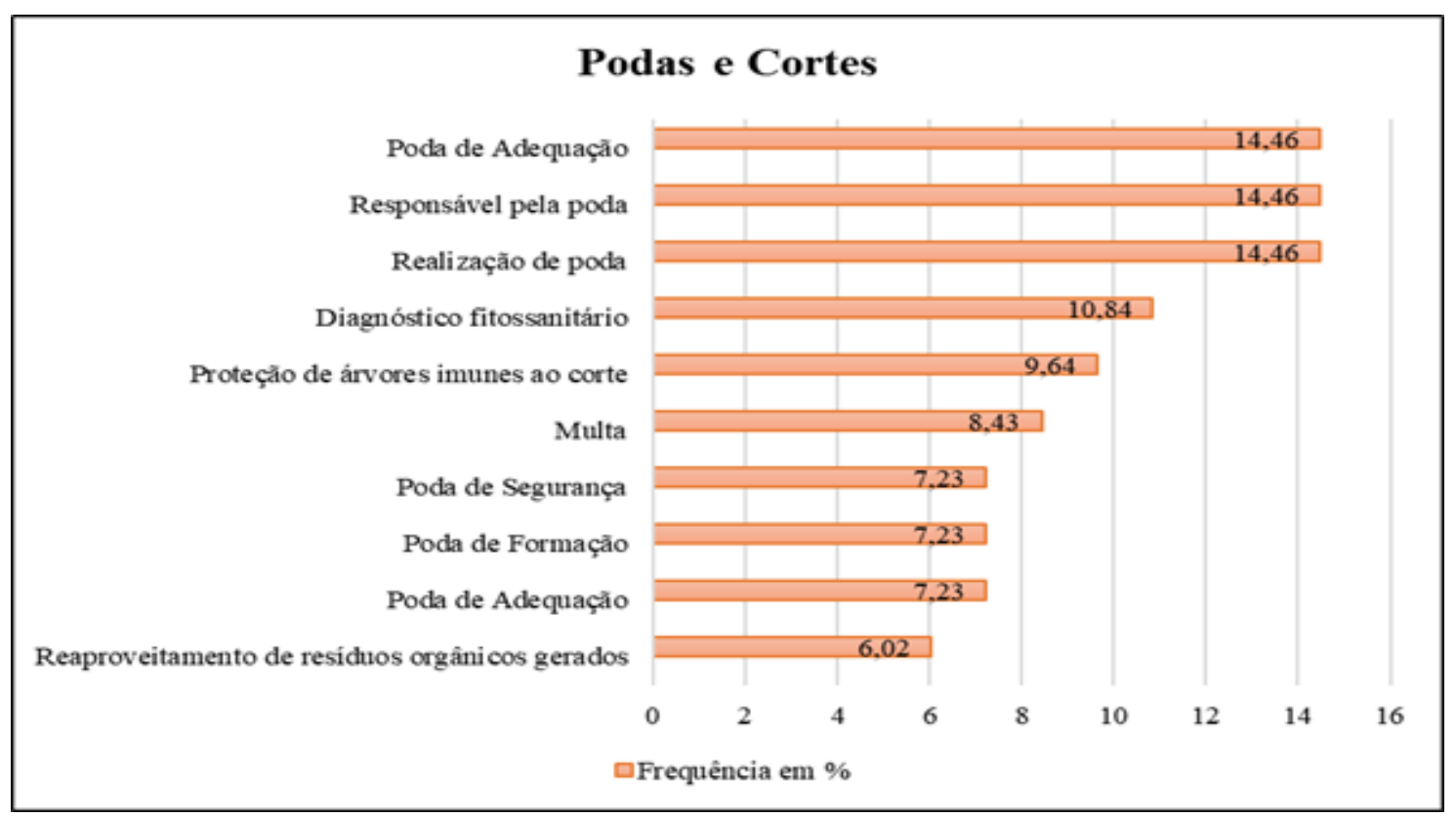

Figura 5. Distribuição dos parâmetros observados referente às podas e aos cortes da arborização urbana, em porcentagem, presentes nos PDAU's das capitais brasileiras.

Por conseguinte, é importante a implantação de políticas públicas voltadas para a arborização urbana, pois, além de contribuir para o zoneamento adequado do solo urbano, ainda promove a saúde coletiva. Dessa forma, torna-se importante o engajamento envolvendo a participação social durante a confecção de planos setoriais deste tipo (Sanches et al., 2008), visando à construção de cidades mais saudáveis e sustentáveis. Além disso, engajar e sensibilizar a população torna-se extremamente relevante em relação a este quesito, não sendo fácil trabalhar com o tema "árvore" em práticas educacionais, uma vez que existe um vínculo emocional entre a população e as árvores (Monico, 2001). 
Em relação à adoção de práticas de educação ambiental, 11 capitais apresentaram estratégias voltadas para este parâmetro. Observou-se a existência de programas específicos de educação ambiental voltados para a arborização urbana $(25,4 \%)$, tendo ações efetivas nas escolas e/ou com a comunidade, incluindo a capacitação de pessoal sobre a temática $(16,9 \%)$. Dentre os programas relacionados ao plantio de mudas e de espécies nativas, destaca-se o Programa Plante a Vida do município de Goiânia-GO, que incentiva a distribuição de mudas de espécies nativas do cerrado para a população, buscando valorizar a flora local. Ainda assim, a realização de palestras, oficinas e demais meios de sensibilização $(8,5 \%)$, a elaboração de material didático, incluindo cartilhas, folhetos e cartazes $(6,8 \%)$ e a parceria de cooperação técnico-científica $(6,8 \%)$ também foram observadas (Figura 6).

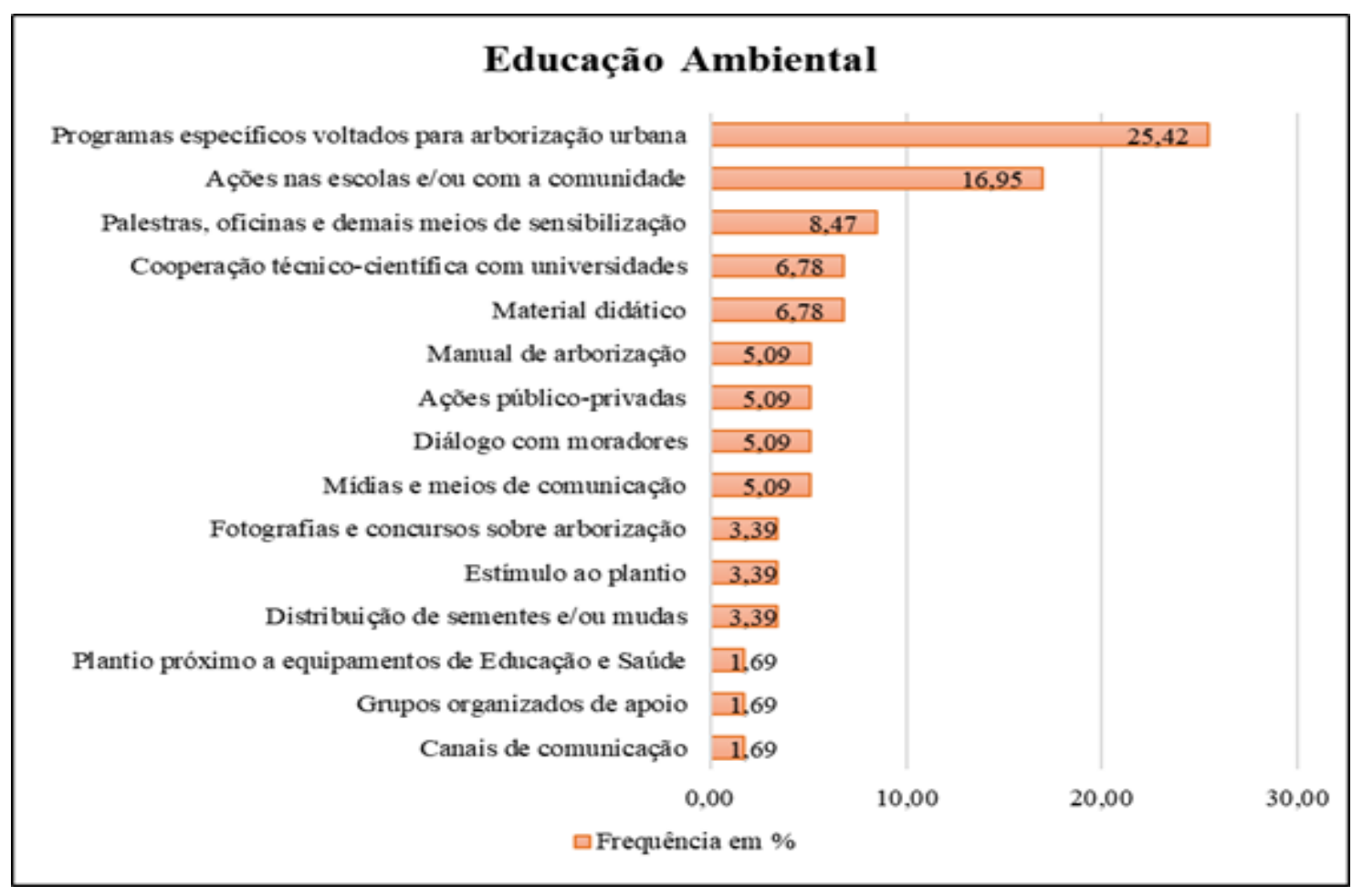

Figura 6. Distribuição dos parâmetros observados na educação ambiental referente à arborização urbana, em porcentagem, presentes nos PDAU's das capitais brasileiras.

Uma das técnicas empregadas como educação ambiental é a doação de mudas, incentivando a população a plantar árvores nativas e manter as ruas arborizadas. Muitos foram os parâmetros observados relacionados à produção de mudas, sendo a produção de mudas e construção de um banco de sementes os mais recorrentes, totalizando 19,0\% dos dados observados. A doação de mudas e sementes vêm em terceiro lugar, com 8,1\% dos dados observados, tendo programas interessantes e relevantes, que incentivam o plantio de espécies nativas e visam à valorização cultural da área. Ainda assim, nota-se a importância de existir uma estrutura própria para a produção de mudas, como é o caso de viveiros e hortos $(8,2 \%)$, a existência de programas específicos para produção e plantio de mudas $(6,8 \%)$ e de incentivo às pesquisas que envolvam a temática $(2,7 \%)$ (Figura 7$)$. 


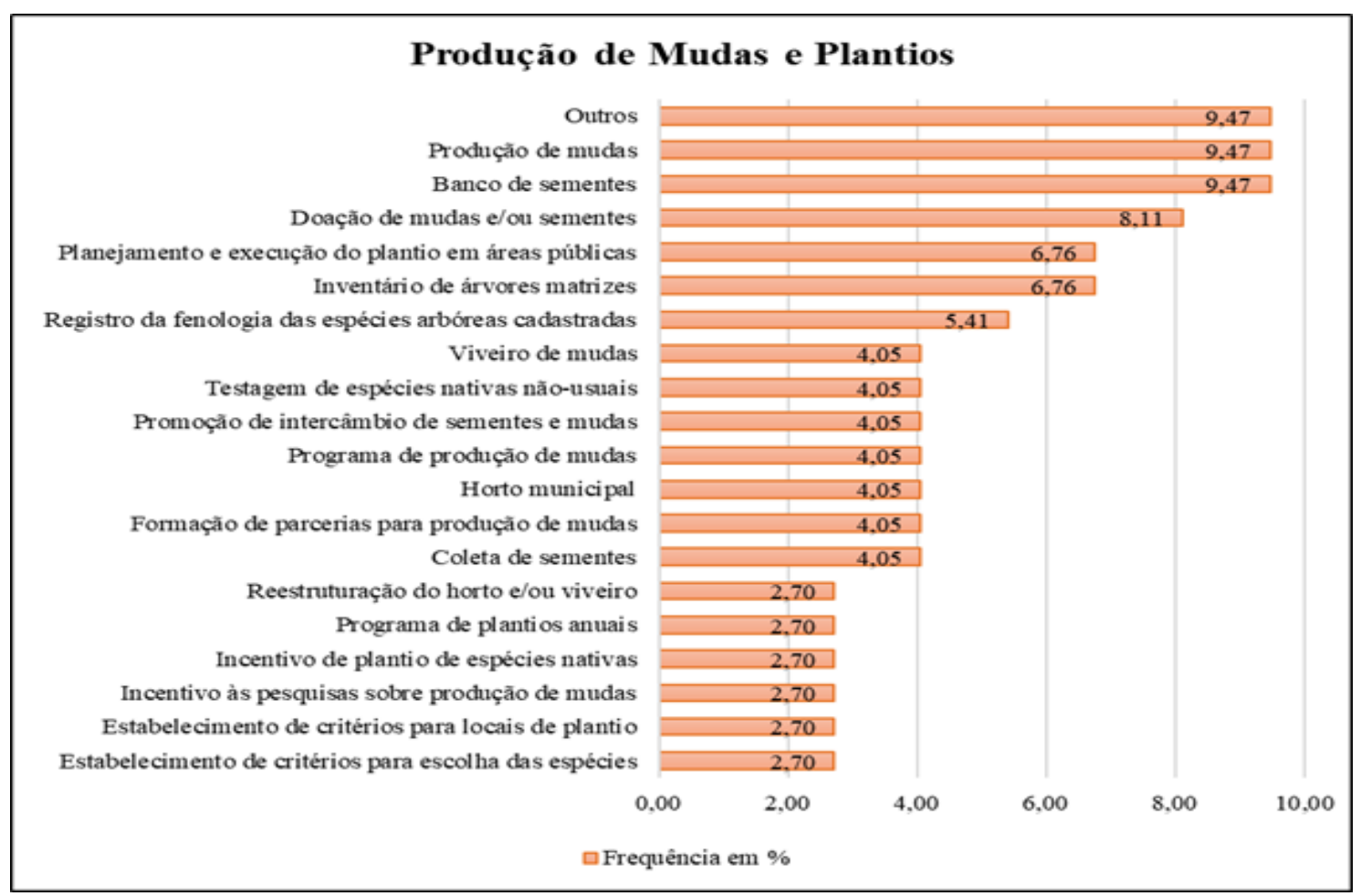

Figura 7. Distribuição dos parâmetros observados na produção de mudas e realização de plantios da arborização urbana, em porcentagem, presentes nos PDAU's das capitais brasileiras, em que "Outros" representa os seguintes parâmetros: resgate de plantas jovens, plantio de mudas em técnicas de educação ambiental, plantios compensatórios, plantio conforme legislação préestabelecida, guia próprio sobre produção e plantio de mudas, cadastramento de mudas e de plantios realizados e atendimento das mudas à padrões de qualidade previamente estabelecidos.

Para realizar o plantio dessas mudas, torna-se necessário ter especificações técnicas que contribuam para gestão eficiente da arborização urbana. Vale lembrar que quando se delega à população a tarefa de implantação das mudas é importante que a mesma seja orientada sobre a técnica e local adequado para plantio.

Os resultados demonstraram uma maior preocupação dos planos com 0 monitoramento e manutenção $(18,1 \%)$ e com os procedimentos a se seguir na realização de um plantio $(18,1 \%)$. A preocupação com o porte e com a origem das espécies a serem utilizadas também foi recorrente, totalizando $32,0 \%$ dos dados analisados. A dimensão da copa $(12,5 \%)$, o jeito que é feito o processo de coveamento $(12,5 \%)$ e a época de plantio $(6,9 \%)$ (Figura 8) também foram relevantes, destacando a importância de utilizar a estação chuvosa a favor da implantação da arborização urbana, uma vez que as chuvas contribuirão para o pleno desenvolvimento da muda plantada.

Brun et al. (2008) relataram a importância de haver uma legislação específica nos municípios que incentive a criação e conservação destes locais nas cidades brasileiras. Para Albuquerque et al. (2018), a existência desse tipo de política objetiva a construção de uma cidade saudável e menos poluída. No entanto, como pode ser observado na análise das capitais das unidades federativas brasileiras, consideradas polos de suas regiões, ainda faltam planos setoriais na área, uma vez muitos gestores enxergam a arborização urbana como sinônimo de gastos adicionais nas contas municipais (Brun et al., 2008). Nesse contexto, a adoção de regramentos específicos para medidas mitigadoras e compensatórias atua diretamente no planejamento e na manutenção da arborização urbana. 


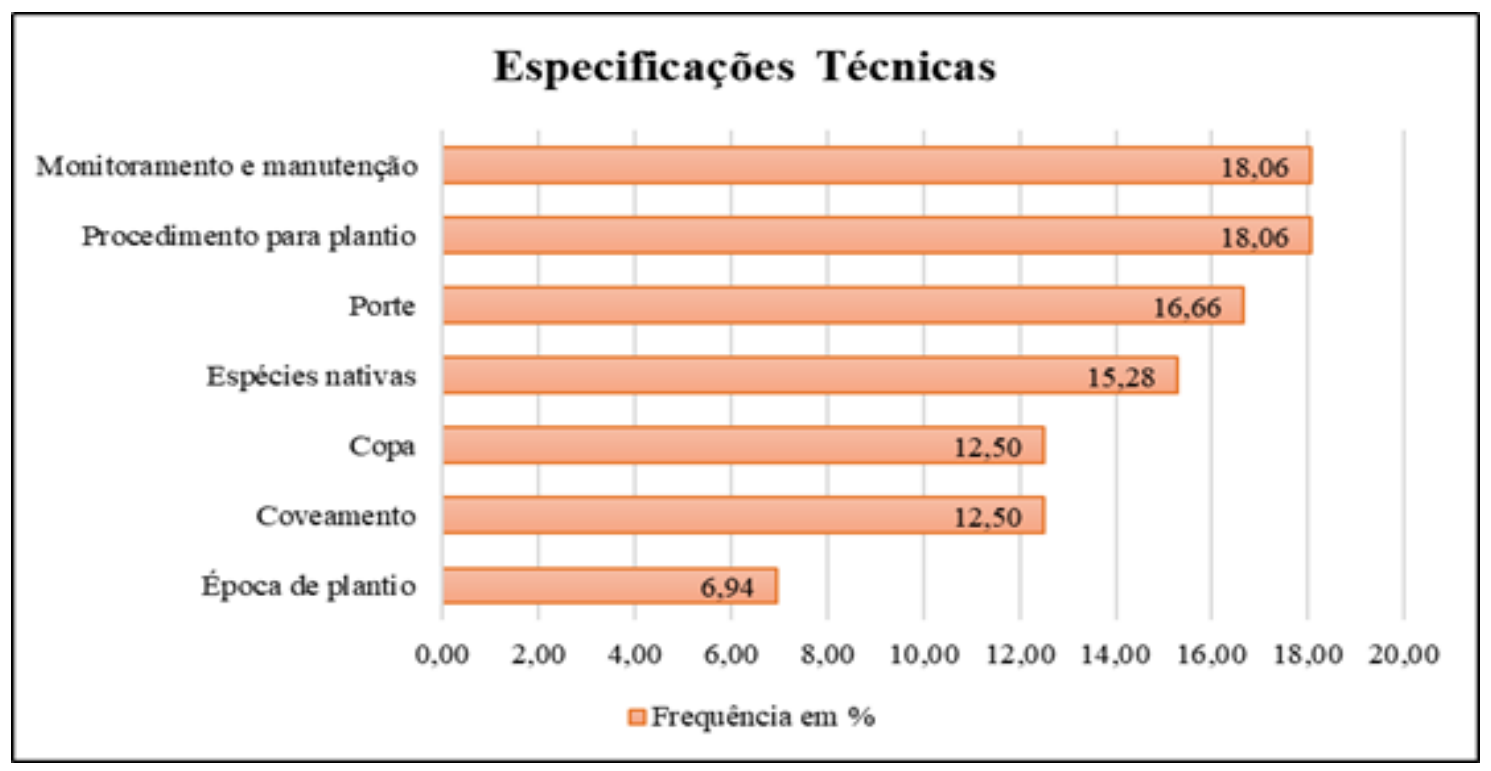

Figura 8. Distribuição dos parâmetros observados nas especificações técnicas da arborização urbana, em porcentagem, presentes nos PDAU's das capitais brasileiras.

Em relação às medidas mitigadoras e compensatórias (Figura 9) estas deverão ser realizadas em $21,9 \%$ dos casos analisados, que representam a supressão da arborização, sendo a aquisição e plantio de mudas $(18,8 \%)$ e a adoção de medidas mitigadoras $(15,6 \%)$ as mais frequentes. A recuperação de áreas que foram degradadas e a execução da arborização urbana totalizaram 25,0\% dos dados coletados (Figura 9). Ainda assim, a compensação por danos não mitigáveis, $(3,1 \%)$ e a existência de indenizações $(3,1 \%)$, apesar de menos frequentes, ainda estão presentes.

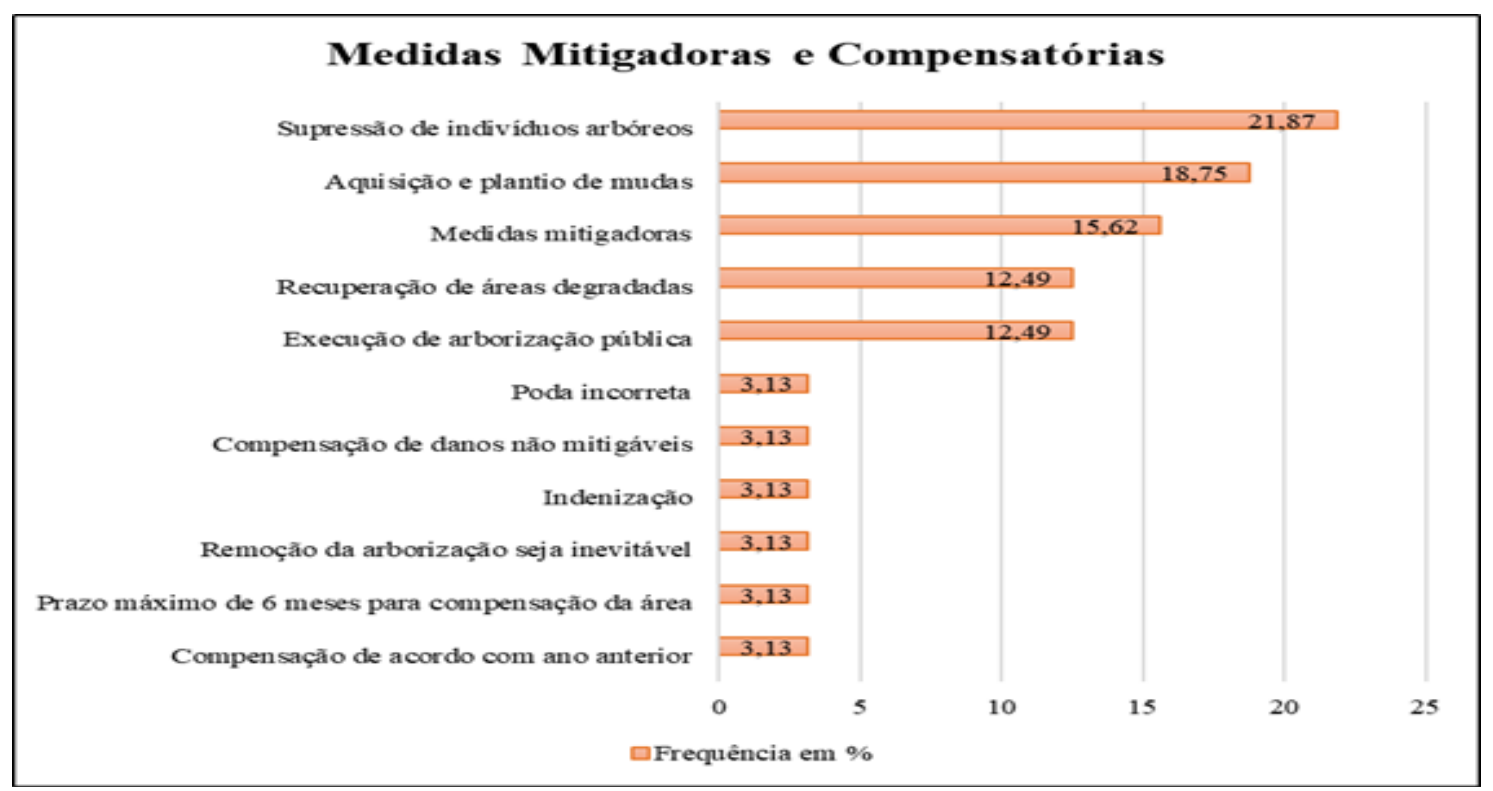

Figura 9. Distribuição dos parâmetros observados referente às medidas mitigadoras e compensatórias da arborização urbana, em porcentagem, presentes nos PDAU's das capitais brasileiras. 
A arborização em área urbana é capaz de proporcionar tanto benfeitorias ambientais, como, também, melhorias na saúde da população, tendo estudos que demonstram a relação entre esses recursos e a diminuição da mortalidade devido "à melhoria da saúde mental, o aumento do engajamento social, a redução da exposição à poluição e o aumento da atividade física" (James et al., 2016) e a melhoria da saúde física e mental em razão do aumento da prática de exercícios físicos e do nível de relaxamento de quem frequenta estes locais (Londe e Mendes, 2014). Dessa forma, a arborização urbana pode ser vista como uma importante ferramenta de promoção de saúde e contribuir pela melhoria da atual crise urbana e ambiental.

\section{Conclusões}

Os resultados demonstraram que, mesmo em capitais, centros urbanos considerados polos de suas regiões, ainda faltam regramentos legais capazes de gerir e planejar a arborização urbana. A disponibilidade e a transparência no acesso a tais documentos acabam por sensibilizar a população em relação ao direito que ela possui frente o acesso aos benefícios advindos dos indivíduos arbóreos.

A falta de políticas públicas no país que viabilizem tais espaços favorece tanto a carência destes recursos no meio urbano, como, também, o surgimento de transtornos e danos à comunidade pelo defasado gerenciamento destes locais. Nesse sentido, a arborização urbana pode e deve ser vista como uma política de promoção de saúde e de planejamento urbano por parte dos órgãos reguladores.

Por fim, concluiu-se que relacionar a existência da arborização urbana com políticas públicas de planejamento promove os benefícios deste atributo para o bem-estar social e a qualidade ambiental das cidades. Municípios com um PDAU robustos e efetivamente implantados são capazes de planejar e gerir a implantação e a manutenção da arborização, evitando possíveis danos e transtornos oriundos da falta de planejamento.

\section{Agradecimentos}

O presente trabalho foi realizado com apoio da Coordenação de Aperfeiçoamento de Pessoal de Nível Superior - Brasil (CAPES) - Código de Financiamento 001.

\section{Conflito de interesses}

Os autores declaram não haver conflito de interesses.

\section{Referências}

Albuquerque, M. M. G.; Zanella, M. E.; Dantas, E. W. C. Política pública, arborização e sustentabilidade: o caso do município de Fortaleza. REDE - Revista Eletrônica do PRODEMA, v. 12, n. 3, p. 69-77, 2018. https://doi.org/10.22411/rede2018.1203.07

Bargos, D. C.; Matias, L. F. Áreas verdes urbanas: um estudo de revisão e proposta conceitual. Revista da Sociedade Brasileira de Arborização Urbana, v. 6, n. 3, p. 172188, 2011.

Brun, F. G. K.; Fuchs, R. H.; Brun, E. J.; Araújo, L. E. B. Legislações municipais do Rio Grande do Sul referentes à arborização urbana: estudo de casos. Revista da Sociedade Brasileira de Arborização Urbana, v. 3, n. 3, p.44-64, 2008. 
Cunha, V. L. C. M.; Magalhães, L. M. S.; Freitas, W. K.; Mendonça, B. A. F. Conflitos da arborização com elementos urbanos na Cidade de Valença, Estado do Rio de Janeiro. Revista da Sociedade Brasileira de Arborização Urbana, v. 15, n. 2, p. 28-41, 2020. https://doi.org/10.5380/revsbau.v15i2.69850

Dadvand, P.; Bartoll, X.; Basagaña, X.; Dalmau-Bueno, A.; Martinez, D.; Ambros, A.; Cirach, M.; Triguero-Mas, M.; Gascon, M.; Borrell, C.; Nieuwenhuijsen, M. J. Green spaces and general health: Roles of mental health status, social support, and physical activity. Environment International, v. 91, p.161-167, 2016. https://doi.org/10.1016/ j.envint.2016.02.029

Dobbert, L. Y.; Zanlorenzi, H. C. P. Arborização urbana e conforto térmico: um estudo para a Cidade de Campinas/SP Brasil. Revista LABVERDE, n. 9, p.73-85, 2015. https://doi.org/10.11606/issn.2179-2275.v0i9p73-85

Dover, D. C.; Belon, A. P. The health equity measurement framework: A comprehensive model to measure social inequities in health. International Journal For Equity in Health, v. 18, n. 1, Article number 36, 2019. https://doi.org/10.1186/s12939-019-0935-0

Duarte, T. E. P. N.; Angeoletto, F.; Richard, E.; Vacchiano, M. C.; Leandro, D. S.; Bohrer, J. F. C.; Leite, L. B.; Santos, J. W. M. C. Arborização urbana no Brasil: um reflexo de injustiça ambiental. Terr@ Plural, v. 11, n. 2, p. 291-303, 2017. https://doi.org/10.5212/ TerraPlural.v.11i2.0008

Duque, A. M.; Peixoto, M. V.; Lima, S. V. M. A.; Goes, M. A. O.; Santos, A. D.; Araújo, K. C. G. M.; Nunes, M. A. P. Analysis of the relationship between life expectancy and social determinants in a North-Eastern Region of Brazil, 2010-2017. Geospatial Health, v. 13, n. 2, p. 345-352, 2018. https://doi.org/10.4081/gh.2018.702

Gil, A. C. Como elaborar projetos de pesquisa. 4. ed. São Paulo: Atlas, 2002.

Gozalo, G. R.; Morillas, J. M. B.; González, D. M.; Moraga, P. A. Relationships among satisfaction, noise perception, and use of urban green spaces. Science of the Total Environment, v. 624, p.438-450, 2018. https://doi.org/10.1016/j.scitotenv.2017.12.148

Hunter, R. F.; Cleland, C.; Cleary, A.; Droomers, M.; Wheeler, B.; Sinnett, D.; Nieuwenhuijsen, M.; Braubach, M. Environmental, health, wellbeing, social and equity effects of urban green space interventions: A meta-narrative evidence synthesis. Environment International, v. 130, 104923, 2019. https://doi.org/10.1016/j.envint.2019.104923

IBGE - Instituto Brasileiro de Geografia e Estatística. Pesquisa Nacional por Amostra de Domicílios Contínua - PNAD Contínua. 2020. Disponível em: $<$ https://www.ibge.gov.br/estatisticas/sociais/trabalho/9173-pesquisa-nacional-poramostra-de-domicilios-continua-trimestral.html?=\&t=resultados $>$. Acesso em: 08 jul. 2020.

James, P.; Hart, J. E.; Banay, R. F.; Laden, F. Exposure to greenness and mortality in a nationwide prospective cohort study of women. Environmental Health Perspectives, v. 124, n. 9, p. 1344-1352, 2016. https://doi.org/10.1289/ehp.1510363

Lee, A. C. K.; Jordan, H. C.; Horsley, J. Value of urban green spaces in promoting healthy living and wellbeing: prospects for planning. Risk Management and Healthcare Policy, v. 8, p. 131-137, 2015. https://doi.org/10.2147/RMHP.S61654

Lima, G. V. B. A.; Pereira, M. M.; Ribeiro Junior, C. R.; Azevedo, L. E. C.; Araújo, I. R. S. O direito à cidade arborizada: a arborização urbana como indicador da segregação socioeconômica em Belém do Pará. Revista da Sociedade Brasileira de Arborização Urbana, v. 15, n. 1, p. 79-96, 2020. https://doi.org/10.5380/revsbau.v15i1.69694 
Liu, H.; Li, F.; Li, J.; Zhang, Y. The relationships between urban parks, residents' physical activity, and mental health benefits: A case study from Beijing, China. Journal of Environmental Management, v. 190, p. 223-230, 2017. https://doi.org/10.1016/ j.jenvman.2016.12.058

Londe, P. R.; Mendes, P. C. A influência das áreas verdes na qualidade de vida urbana. Hygeia - Revista Brasileira de Geografia Médica e da Saúde, v. 10, n. 18, p. 264-272, 2014.

Lucon, F.; Longo, R. Alterações na temperatura da superfície do solo em função de diferentes formas de cobertura superficial do solo. Revista Gestão \& Sustentabilidade Ambiental, v. 8, n. 4, p. 523-538, 2019.

Maricato, E. Para entender a crise urbana. CaderNAU - Cadernos do Núcleo de Análises Urbanas, v. 8, n. 1, p. 11-22, 2015.

Monico, I. M. Árvores e arborização urbana na Cidade de Piracicaba/SP: um olhar sobre a questão à luz da educação ambiental. Piracicaba: Universidade de São Paulo, 2001. (Dissertação de mestrado).

Osako, L. K.; Takenaka, E. M. M.; Silva, P. A. Arborização urbana e a importância do planejamento ambiental através de políticas públicas. Revista Científica "ANAP Brasil", v. 9, n. 14, p. 1-8, 2016. https://doi.org/10.17271/1984324091420161318

Sanches, P. M.; Costa, J. A.; Silva Filho, D. F. Análise comparativa dos planos diretores de arborização enquanto instrumento de planejamento e gestão. Revista da Sociedade Brasileira de Arborização Urbana, v. 3, n. 4, p. 53-74, 2008.

Shams, J. C. A.; Giacomeli, D. C.; Sucomine, N. M. E. Emprego da arborização na melhoria do conforto térmico nos espaços livres públicos. Revista da Sociedade Brasileira de Arborização Urbana, v. 4, n. 4, p. 1-16, 2009.

Silva, G. M. A.; Brun, E. J.; Brun, F. G. K.; Callegaro, R. M.; Costa, C. D. P. Metanálise do conteúdo técnico de diferentes Planos Diretores de Arborização Urbana do Brasil. Revista de Extensão e Estudos Rurais, v. 8, n. 2, p. 62-83, 2020. https://doi.org/10.36363/ rever82201962-83

Siqueira-Gay, J.; Dibo, A. P. A.; Giannotti, M. A. Vulnerabilidade às ilhas de calor no Município de São Paulo: uma abordagem para a implantação de medidas mitigadoras na gestão urbana. Revista de Gestão Ambiental e Sustentabilidade, v. 6, n. 2, p. 105-123, 2017.

WHO - World Health Organization. Urban planning essential for public health. 2010. Disponível em: <https://www.who.int/mediacentre/news/releases/2010/urban_health_ 20100407/en/>. Acesso em: 19 abr. 2020.

Informação da Licença: Este é um artigo Open Access distribuído sob os termos da Licença Creative Commons Attribution, que permite uso irrestrito, distribuição e reprodução em qualquer meio, desde que a obra original seja devidamente citada. 